\title{
Potentials, Limitations and Future Directions of MR Contrast Media in Ablation Therapies
}

\author{
Saeed $\mathrm{M}^{*}$, Liang A, Hetts SW and Wilson MW \\ Department of Radiology and Biomedical Imaging, University of California San Francisco, California, USA
}

${ }^{*}$ Corresponding author: Saeed M, Professor, Department of Radiology and Biomedical Imaging, University of California San Francisco, 185 Berry Street, Suite 350, San Francisco, CA 94107-5705, USA, Fax: 415-3539423, Tel: 415-514-6221, E-mail: Maythem.Saeed@ucsf.edu

Citation: Saeed M, Liang A, Hetts SW, Wilson MW (2016) Potentials, Limitations and Future Directions of MR Contrast Media in Ablation Therapies. J Adv Radiol Med Image 1(2): 201. doi: 10.15744/24565504.1.201

Received Date: June 19, 2016 Accepted Date: October 22, 2016 Published Date: October 25, 2016

\begin{abstract}
MR contrast media have become an indispensable part of magnetic resonance (MR) imaging, but their roles in ablation therapies are still controversial. The interactions between physical/biological properties of $M R$ contrast media (Longitudinal $=\mathrm{T}_{1}$, transverse $=\mathrm{T}_{2}$ and susceptibility $=\mathrm{T}_{2}{ }^{*}$ relaxation times) and diseased tissues (perfusion, edema, hemorrhage and coagulative necrosis) play important roles in differentiating pathologic and ablated tissues. Unlike iodinated contrast media, MR contrast media are not directly measurable on MR images, but their effects on adjacent nuclei are observed. Paramagnetic and superparamagnetic MR contrast media, represented by gadolinium chelates and iron oxide particles, demarcate tumors and cardiac ablation. Soon after ablation, gadolinium chelates enhance the peri-ablated zone, but do not enhance the core of coagulative necrosis. The enhancement of peri-infarct zone suggests the presence of some nonviable tumor, intact microvessels, and moderate expansion of extracellular compartment. MR contrast media are also beneficial in highlighting hemorrhage and injuries in neighboring organs due to improper targeting of the lesions. Additionally, it can be used in monitoring vascular invasion and metastasis of the tumors. The provision of characteristics of pre- and post-ablation tissue characteristics with MR contrast media might be helpful in complex ablation procedures. The development of specific and stable molecular MR contrast media could help in optimizing a personalized therapeutic strategy. The scope of this review is not on the ablation techniques but on the types of MR contrast media that are currently used in tissue ablation, their distribution, the appearance of ablated tissues on contrast enhanced MRI, and the limitations of the usage of some MR contrast media.
\end{abstract}

Keywords: MR Contrast Media; MR Imaging; Interventional Radiology; Tissue Ablation; Tumors; Cardiac Arrhythmia

\section{Introduction}

Tissue biopsy is a standard method for differentiating tumors from fibrotic tissues and is considered to be an invasive procedure and subject to sampling error. This procedure has been associated with complications, such as excessive bleeding (hemorrhage), infection and puncture damage to nearby healthy tissue or organs. Ultrasonography, computed tomography and/or magnetic resonance (MR) imaging are noninvasive techniques that can be used for characterizing and monitoring ablated tissues [1]. On the other hand, ablation procedures can be performed invasively and noninvasively in surgery using heat, ice or erosive chemicals. It has been shown that tissues subjected to temperatures higher than $42{ }^{\circ} \mathrm{C}$ or below zero ${ }^{\circ} \mathrm{C}$ are considered thermally stressed, while tissues subjected to temperatures above $60{ }^{\circ} \mathrm{C}$ or below $-15^{\circ} \mathrm{C}$ are considered necrotic [2]. Thus, there is a pressing need to develop non-invasive method suitable to delineate tumors and characterize ablated scar tissue in patients. MR contrast media were clinically introduced in late 1980. While these compounds are pivotal for tumor detection, characterization and treatment planning, their roles are controversial during ablation. MR contrast media provide a wealth of tissue contrast depending on the acquisition sequences used. Today the clinical applications of MR contrast media have been substantially expanded along with the advancement in interventional procedures and new therapies [3]. One of the therapies is chemical and thermal ablation, which is used to permanently destroy tumors [4,5] or abnormal cardiac electric currents [6-9].

MR contrast media represent an alternative option for patients at risk of adverse reactions to iodinated contrast media. These compounds shorten the T1 and T2 relaxation times of the tissues. The advantages of MR imaging arise from: the superior soft tissue contrast, noninvasiveness, lack of radiation, high spatial and temporal resolution, inherent 3D data acquisition with unlimited orientation, intrinsic contrast exploitable for tissue characterization, sensitivity to blood flow, temperature measurement, and the different ways in which MR signal produced and processed [10-14]. Recently investigators demonstrated that a single loopless antenna could be configured to acquire high-spatial-resolution MR images at 3T, locally deliver radiofrequency energy, monitor that delivery with MR thermometry, and assess the outcome of the ablation by means of relaxometry [15]. 
The most commonly used MR contrast media are gadolinium chelates and iron oxide particles. Criteria for clinical suitability of contrast media include diagnostic efficacy, safety, stability, clearance and cost. To our knowledge, there is no review article addressing the roles of MR contrast media in characterizing chemical and thermal (cryoablation and hyperthermia) ablation therapies, thus the scope of this review is on the types of MR contrast media that are currently used in tissue ablation, their distribution, the appearance of ablated tissues on contrast enhanced MRI, and the limitations of the usage of some MR contrast media. Excellent reviews have been recently published on ablation techniques [16-19].

\section{MR Contrast Media}

On MRI, image contrast is a function of proton density and tissue relaxation times. The term "relaxivity" describes how signals deteriorate with time and become weaker or broader. The deterioration of an MR signal is analyzed in terms of two separate processes, each with their own time constants. One process, associated with $\mathrm{T}_{1}$ (spin-lattice relaxation time), is responsible for the loss of signal intensity. $\mathrm{T}_{1}$ relaxation is measured using a time constant called $\mathrm{T}_{1}$ (in milliseconds, $\mathrm{msec}_{\text {). }} \mathrm{T}_{1}$ is defined as the time when $63 \%$ of the longitudinal magnetization has recovered. The other process, which is associated with $\mathrm{T}_{2}$ (spin-spin relaxation), is responsible for the broadening of the signal. $\mathrm{T}_{2}$ relaxation is measured using a time constant called $\mathrm{T}_{2}$ (usually reported in milliseconds, $\mathrm{msec}$ ). $\mathrm{T}_{2}$ is defined as the time when $63 \%$ of the transverse magnetization has decayed. $\mathrm{T}_{2}^{*}$ results principally from inhomogeneity in the main magnetic field. These inhomogeneities result from distortions of susceptibility-induced field produced by the tissue or other materials placed within the field. The $\mathrm{T}_{2}{ }^{*}$ relaxation time is always shorter than the $\mathrm{T}_{2}$ relaxation time and is typically in milliseconds for water samples in imaging magnets. Values differ in different tissues/organs and pathologies.

$\mathrm{T}_{1}$ weighted imaging is useful for assessing structures that are high in fat or structures that are near water filled structures, such as joints, which otherwise would be hard to be seen on $\mathrm{T}_{2}$ weighted imaging. On the other hand, $\mathrm{T}_{2}$ weighted imaging is useful for assessing water-rich structures such as inflammation associated with edema. These lesions appear bright on this sequence. Other MR are called $\mathrm{T}_{2}{ }^{*}$ or susceptibility sequences. These sequences, which are used to accentuate local magnetic homogeneity effects, aid in the detection of hemorrhage and calcifications.

MR contrast media have unpaired electrons, which generate large fluctuating magnetic fields within the MRI environment. These compounds have included the use of several magnetic elements such as gadolinium $\left(\mathrm{Gd}^{3+}\right)$, manganese $\left(\mathrm{Mn}^{2+}\right)$, dysprosium $\left(\mathrm{Dy}^{3+}\right)$ and iron $\left(\mathrm{Fe}^{3+}\right)$. The relaxation time is proportional to the square of the magnetic moment of paramagnetic elements. Paramagnetic (represented by gadolinium chelates) and superparamagnetic (represented by iron oxide particles) MR contrast media have different numbers of unpaired electrons. For example, gadolinium and iron have 7 and 5 unpaired electrons, respectively. The magnetic field produced by an electron is stronger than by $\mathrm{H}^{1}$ protons. It has been shown that gadolinium and manganese affect $\mathrm{T}_{1}$ and $\mathrm{T}_{2}$ of protons in the tissue, hence whether the tissue signal increases on $\mathrm{T}_{1}$ sequences or decreases on $\mathrm{T}_{2}$ sequences is depending on their local concentrations [20]. On $\mathrm{T}_{2}$ weighted sequences, iron and dysprosium generate local magnetic field gradients that disrupt the homogeneity of the magnetic field, which causes signal reduction on $\mathrm{T}_{2}$ sequences [21].

MR contrast media are also classified as extracellular $(<2500 \mathrm{Da})$ or blood pool (intravascular) ( $>38 \mathrm{kDa})$. Clinically available extracellular MR contrast media are $\mathrm{T}_{1}$-enhancing contrast media with a molecular weight of 500-2500 Da. Efficient $\mathrm{T}_{1}$-enhancing MR contrast media have a high magnetic susceptibility effect and can potentially be used to exert susceptibility with appropriate dosages and imaging sequences [22]. Blood pool MR contrast media have the following advantages over extracellular media $[20,23]$ :

1. Provide longer enhancement and imaging time because of their prolonged plasma half-life ( $\approx 90$ min) compared to extracellular MR media (17-20 min);

2. Provide better contrast to noise ratio on MR angiography;

3. Provide high dose efficiency that is related to the high $R_{1}$ relaxivity;

4. Provide accurate information in regard to myocardial blood volume and perfusion;

5. A sensitive marker for microvascular hyperpermeability and integrity.

Gadolinium based blood pool contrast media have been used for detecting the increases in vascular density and permeability in tumors. They are also used for testing the effectiveness of tumor therapies [24]. Kholmovski et al. [25] showed in swine that acute atrial lesion could be visualized as early as 3 minutes after RF ablation and could persist for up to 3 hours after the injection of the blood pool contrast agent (Ablavar, Lantheus Medical Imaging Inc., N. Billerica, MA). This contrast medium showed more distinct enhancement predominantly in the ablated regions and not so much in fibrous tissues. However, these agents have rarely been used in patients before or after ablation therapies.

\section{Gadolinium Chelates}

MR contrast media are delivered either intravenously or locally [26-28]. Intravenously injected gadolinium chelates enhance the visibility of ablated tissue and inflammation in the peri-ablated zone [14]. These compounds are also used to provide information on the integrity of microvessels, blood volume, perfusion and probing of microvascular integrity [29,30]. MR contrast media could be mixed with ethanol [31] or emboli and delivered locally to highlight the injection sites [32,33]. 
Gadolinium ion is quite toxic to patients. However, chelated gadolinium agents are less toxic because they are excreted rapidly through the kidneys before the free ion is released in the body. The chelates reduce the chances of toxicity that could result from exposure to free gadolinium. However, certain patients who received gadolinium-based contrast media appeared to be at an increased risk for developing serious nephrogenic systemic fibrosis. A possible association between nephrogenic systemic fibrosis and gadolinium-based contrast media was first reported in May 29, 2006 [34]. Patients at risk are those with acute or chronic severe renal insufficiency (glomerular filtration rate $<30 \mathrm{~mL} / \mathrm{min} / 1.73 \mathrm{~m}^{2}$ ) or hepato-renal syndrome. Since December 2006, FDA has continued to investigate reports of nephrogenic systemic fibrosis in patients who received gadolinium-based contrast media to help define risk factors for nephrogenic systemic fibrosis. In addition, the FDA has requested the manufacturers of all gadolinium-based contrast media to add a new Boxed Warning and "Warning" section to their labels to describe the risk of developing nephrogenic systemic fibrosis.

The effects of MR contrast media on signal intensity are described in terms of $T_{1}$ and $T_{2}$ relaxivities. The relaxivity of a contrast medium is defined as the slope of the curve of $1 / \mathrm{T}_{1}\left(\mathrm{~T}_{1}\right.$ relaxation rate) or $1 / \mathrm{T}_{2}\left(\mathrm{~T}_{2}\right.$ relaxation rate plotted against the concentration of a contrast medium). The relaxation rate ratio $\left(\mathrm{R}_{2} / \mathrm{R}_{1}\right)$ can be used to determine whether the medium is causing predominant $\mathrm{T}_{2}$ shortening with a loss of signal on $\mathrm{T}_{2}$-weighted images $\left(\mathrm{R}_{2}\right.$ significantly greater that $\left.\mathrm{R}_{1}\right)$ or $\mathrm{T}_{1}$ shortening with an increased signal on $\mathrm{T}_{1}$-weghted images $\left(\mathrm{R}_{1}>\mathrm{R}_{2}\right)$. Investigators also found that $\mathrm{T}_{1}$-enhancing media had high magnetic susceptibility effects with high doses and specific imaging sequences $[35,36]$. Furthermore, the interactions between pathologic tissues (edema, necrosis or hemorrhage) and physical/biophysical properties of $\mathrm{MR}$ contrast media $\left(\mathrm{T}_{1}, \mathrm{~T}_{2}\right.$ and $\left.\mathrm{T}_{2}{ }^{*}\right)$ also play important roles in differentiating healthy from pathologic tissues.

\section{Iron Oxide Particles}

Iron oxide particles are highly biocompatible due to the natural metabolism of iron in vivo. They are small enough to extravasate through injured microvessels, where they are engulfed and concentrated by tissue-resident macrophages [37]. John et al. [38] showed that the penetration time of iron oxide particles $(20 \mathrm{~nm}$ in diameter) was directly related to the tissue elasticity. The morphological, structural, and magnetic profiles of iron particles determine their suitability for MR imaging and magnetic hyperthermia/ablation [39,40]. It should be noted that iron oxide particles, not gadolinium chelates, are visible on MRI and histopathology. Therefore it is used to label stem cell therapy and define the sites of injection of local therapies. Figure 1 shows the distribution of locally injected iron oxide particles (Feraheme ${ }^{\mathrm{R}}, 6 \mathrm{mg} / 03 \mathrm{ml}$ ) in the tissue 10 days after delivery.

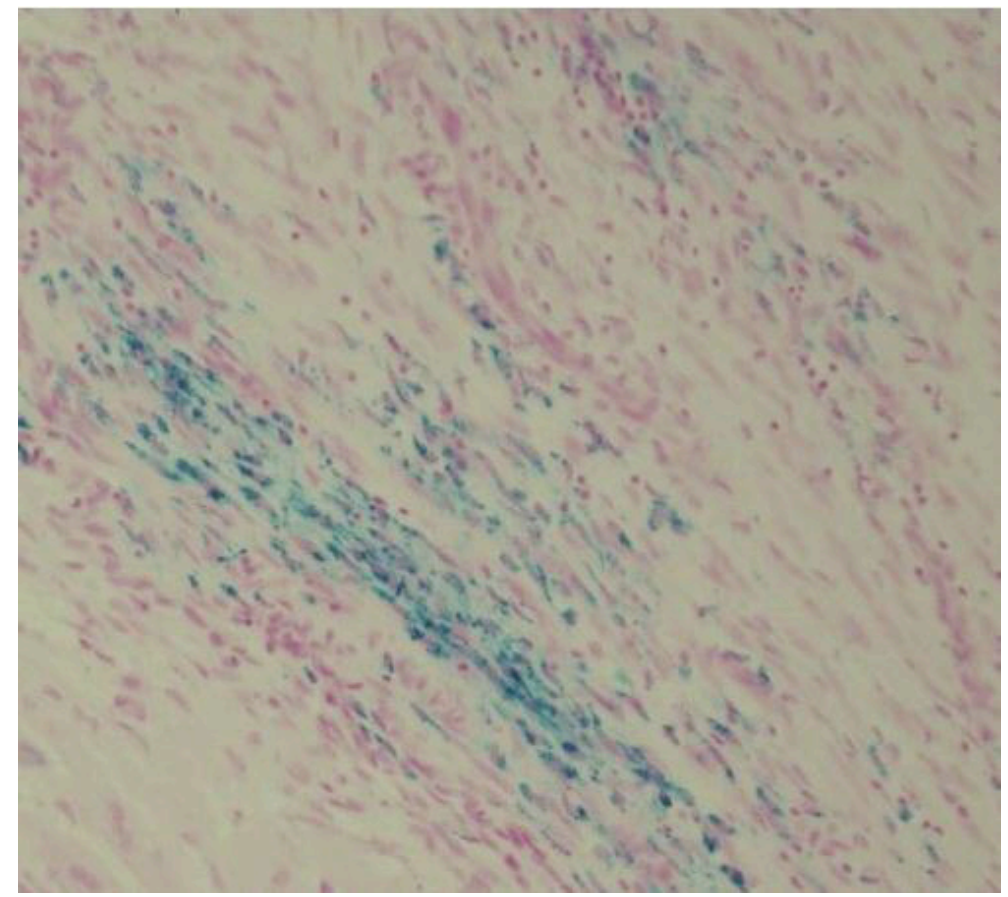

Figure 1: Microscopic section shows the distribution of locally injected iron oxide particles (Feraheme ${ }^{\mathrm{R}}, 6 \mathrm{mg} / 03 \mathrm{ml}$ ) in the tissue 10 days after delivery (40X). Iron oxide particles (blue) are visible on MRI and histopathology; therefore it is used to label the cells in cases of stem cell therapy and to define the sites of injection of local therapies. Gadolinium chelates are invisible on light microscopy

Iron oxide particles consist of an iron oxide core surrounded by a coating of carbohydrate or polymer [41] and are divided into superparamagnetic $(>50 \mathrm{~nm})$ and ultra-small superparamagnetic iron oxide particles $(<50 \mathrm{~nm})$ [42]. The large iron oxide particles are quickly sequestered by reticulaendothelial system. Ultra small superparamagnetic iron oxide particles have longer circulation times in the blood and broader tissue distribution because they avoid reticula-endothelial system sequestration. Superparamagnetic iron oxide particles of 5-8nm undergo glomerular filtration and renal clearance, while particles of greater than $8 \mathrm{~nm}$ with specific surface charges and hydrophobicity are phagocytosed by liver Kupffer cells and cleared via the biliary system [43]. 
Iron oxide particles are taken up by macrophages and infiltrated into infarcted myocardium. Because of the $\mathrm{T}_{2}{ }^{*}$ decay time, the particles create signal loss that can be visualized and quantified on MR imaging [44]. Investigators found that iron oxide particles were specifically taken up only by activated macrophages, but not by undifferentiated monocytes. The iron oxide particles are also accumulating in the tumor tissues due to the large gaps of endothelial lining of new blood vessels. These particles have been used as MR contrast media for imaging, targeting and drug delivery [45-47].

Iron oxide particles have greater magnetic susceptibility than gadolinium-chelates [23,48-50] thus garnering interests in imaging tissue ablation [51-53] and molecular imaging [41]. Iron oxide particles can be detected at molar concentrations, offering sufficient sensitivity for $\mathrm{T}_{2}{ }^{*}$ weighted imaging [45,54]. The ability of iron oxide particles to generate heat upon exposure to an alternating magnetic field made it useful for treatment of deep-seated lesions [55,56] and tumor ablation [56].

Ferumoxtran (Combidex, AMAG Pharmaceutical Inc.) is an iron oxide MR contrast medium that is safe for patients with renal failure and contrast allergy. It provides a stable enhancement during surgery to remove tumors and it remains in the tissue long enough for post-operative MR imaging [57].

\section{Contrast Media Distribution}

The charges, molecular weight and shape of MR contrast media determine their distribution in the body. The distribution of extracellular and blood pool contrast media also depends on the integrity of blood brain barriers and size of the gaps in microvessels, respectively. The distribution of extracellular contrast media in ablated tissue also rests upon sufficient perfusion ( $>30 \%$ of baseline) and the type of transportation (diffusion or convection). Manganese ions, as intracellular medium, distribute actively in the cellular compartment via voltage operated calcium channels [58].

Dynamic gadolinium-chelates imaging demonstrates the distribution of MR contrast media in the vascular compartment. After bolus intravenous injection, the concentration rises in the input artery.

First pass contrast media perfusion imaging has the capability of assessing the dynamics of contrast medium distribution from the microvessels to the interstitial compartment. Many different metrics can be directly or indirectly derived from perfusion imaging; including blood flow, blood volume, mean transit time, permeability surface, peak enhancement, maximum upslope and time to peak [59-61]. This type of acquisition allows the detection of hypervascularized tumors [62]. On the other hand, visualization of the perfused regions is limited to a short time window after bolus injection. Investigators also found that the perfusion in the core of ablated tissue is impaired due to the destruction of the microvessels, resulting in low signal intensity. On delayed contrast enhanced MR imaging, the ablated core also shows no enhancement, but is surrounded by enhanced peri-ablated zone [63]. Figure 2 shows dynamic and delayed contrast enhanced MR images of ablated kidney. Note that on both sequences the ablated lesion appeared as hypoenhanced zone [14].
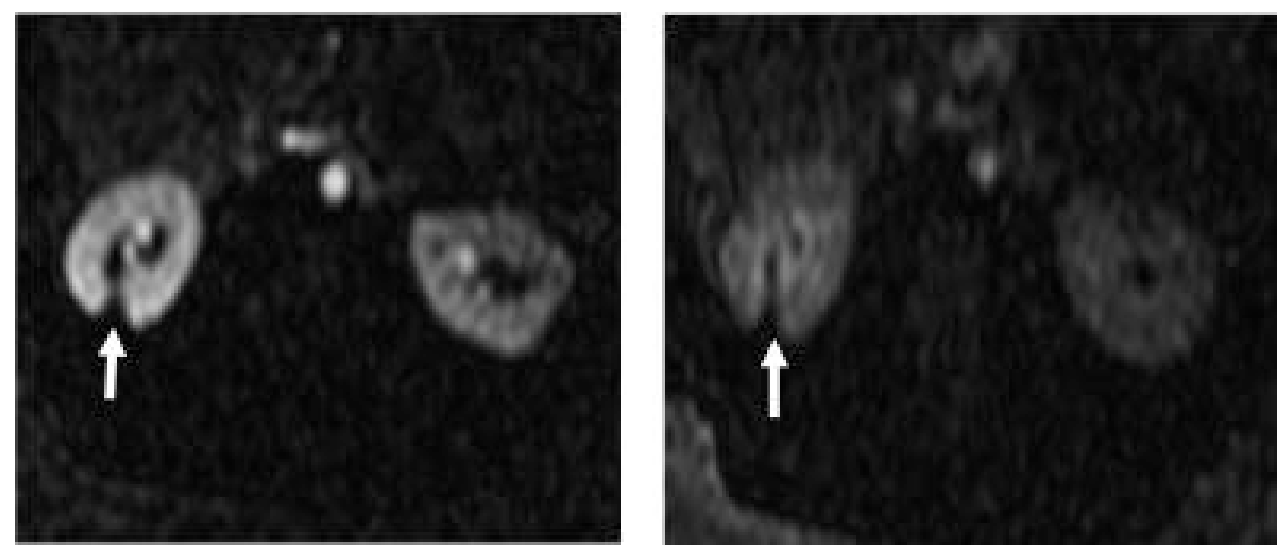

Figure 2: Left: Dynamic MR Image showing the ablated renal lesion during the first passage of Gd-DTPA (0.15 mmol/kg) (arrow). The other kidney was used as control; Right: Delayed contrast enhanced MR image acquired 10 minutes after administration of the contrast medium. On both sequences the ablated lesion appeared as hypoenhanced zone (arrows) [14]

The detection of tumors can be enhanced by applying intracellular contrast media such as mangafodipir trisodium (Mn-DPDP) [64] and bis-Gd-DTPA-mesoporphyrin (Gadophrin-2) [65]. In 14 liver ablation patients, Joarder et al. assessed the number of lesions, ease of puncture planning, conspicuity of lesions, gallbladder, vessels, and surrounding bowel after administration of Mn-DPDP. They observed significant improvement in lesion conspicuity and ease of puncture planning when Mn-DPDP was used. They also found significant improvement in the number of lesions and bowel conspicuity [66]. The effects of Gadophrin-2 for detecting lesions of radiofrequency liver ablation on MR imaging have been experimentally demonstrated in rats bearing liver tumor [67,68]. Investigators found poor contrast among normal liver, ablated lesion, residual and/or intact tumor on unenhanced T1-weighted images. After administration of Gadophrin-2, the signal intensity of the tumor in the liver was time dependent, where signal intensity of the peri-ablated zone was enhanced by $45 \%$ and $90 \%$ in the early and late stage, respectively. As a result, the ablated core appeared as a hypoenhanced region. 
Dendrimers are small nanoparticles $(<15 \mathrm{~nm})$ composed of highly branched synthetic polymers that can harbor smaller particles (e.g., contrast media particles). These intravascular compounds are non-immunogenic and have a prolonged circulation half-life [69]. Dendrimers have also been used for oncology drug delivery and diagnostic imaging model [70]. Investigators found that MR imaging performed with nano-sized contrast media could help to investigate three parallel processes during the carcinogenetic pathways towards dysplasia and full malignancy: 1) the progressive capillarization of the sinusoids together with an increase in the number of arterioles, 2) the progressive loss of biliary polarization of the hepatocyte and the derangement of secretory structure and 3) the progressive nodular depletion of Kupffer cells in mice model [71]. Ringe et al. [72] and Di Martino et al. [73] found that the availability of biphasic contrast media, such as gadoxetate disodium, with vascular and elective hepatocytic uptake, could potentially offer more chances to standardize the hepatocyte carcinoma, while offering a morphological imaging combined with a purely functional imaging. Gadoxetate disodium is a gadolinium-based liver specific MR contrast agent that differs from most of other gadolinium chelates in possessing substantially increased $\mathrm{R}_{1}$ relaxivity in blood. Gadoxetate disodium can be used to either reduce the dose of contrast medium or increase the degree of both vascular and parenchymal contrast enhancement. Furthermore, since about half the amount of gadoxetate disodium is eliminated through the hepatobiliary pathway, liver-specific imaging during the delayed hepatobiliary phase can be performed to improve both lesion detection and characterization. Compared with CT, gadoxetate disodium-enhanced MR imaging yields significantly higher diagnostic accuracy and sensitivity for the detection of new hepatocyte carcinoma in treated patients. MRI with liver-specific contrast agent can be used to confirm the technical success of radiofrequency ablation [74]. Since the fibrous tissue is the main component of ablated tissues, there is a need for specific MR contrast media that has the potential to delineate fibrous tissue at early stage.

\section{Appearance of Treated Tissues on MR Imaging}

Diffusion-weighted, first pass perfusion, magnetization transfer and delayed contrast enhanced MR imaging have been used for identifying the appearance of ablated tissues [75-77]. These imaging sequences can be performed in a single session "one-stop evaluation" before and after ablation. Diffusion-weighted imaging measures the random diffusion of water molecules [76,78]. Tissues with high cellular density or altered cellular membranes have restricted diffusion, which is depicted as signal hyperintensity areas on high $b$-value diffusion-weighted images and hypointensity on the apparent diffusion coefficient maps.

On unenhanced T1-weighted MR images, the signal intensity overlaps among normal, peri-tumor zone and tumor necrosis. On T2-weighted sequences, the peri-ablated zone shows differential enhancement. This differential enhancement has been attributed to the increases in regional perfusion and blood volume in response to temperature changes [79]. After tissue ablation, MR contrast media do not enhance the core of ablated tissue (Figure 3).
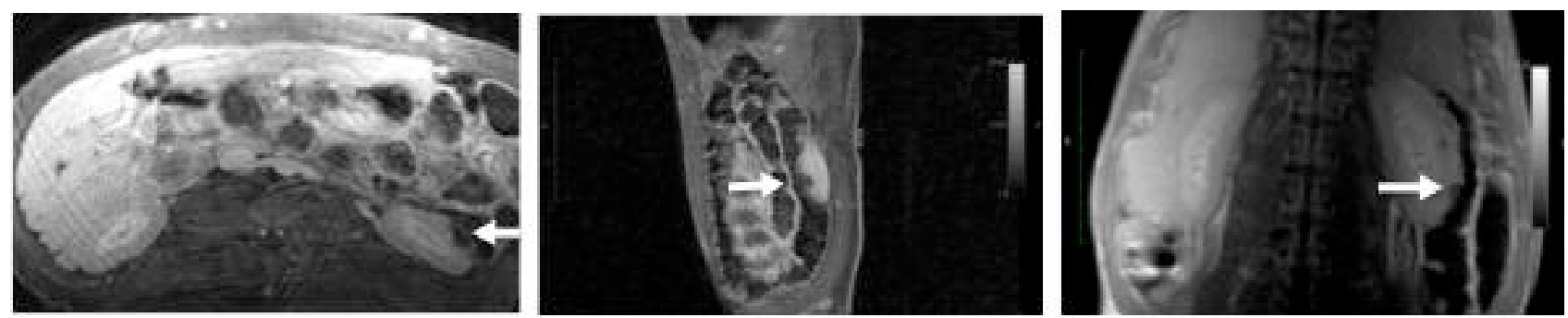

Figure 3: Delayed contrast enhanced MR images in 3 different views acquired 3 hours after thermal ablation. Gd-DTPA (0.15 mmol/ $\mathrm{kg}$ ) was intravenously injected to delineate the ablated tissue. The axial, sagittal and coronal T1-weighted MR images of ablated left kidney show coagulative necrosis as hypoenhanced zone (arrows) [14]

Cardiac ablation is a standard treatment procedure for eliminating different types of cardiac arrhythmia. Investigators used ablating catheter for this purpose followed by administration of MR contrast media to delineate ablated spots [6-9]. Investigators also found that contrast enhanced MR imaging was useful for identifying arrhythmic substrate [80,81]. McGann et al. indicated that contrast enhanced MR imaging had the ability to encompass the target volume through direct imaging of signal enhancement after tissue ablation in patients [8]. An integrated 3D scar reconstruction from delayed gadolinium-enhanced MR imaging was used to facilitate ventricular tachycardia ablation [82] and to confirm/deny the presence of scar after the intervention. Furthermore, there has been increasing interest in visualizing the immediate post ablation injury to better understand its effect on left atrium remodeling and the success of the procedure [83]. Within 24 hours after ablation, dark regions of no-reflow on contrast enhanced MR imaging have been used to correlate with regions of myocardium that eventually become scarred [84,85]. In the heart, ablated myocardium is invisible on $\mathrm{T}_{1}$ weighted images. However, the spatial extent of the lesion was clearly demarcated with this sequence after administration of gadolinium-DTPA [86]. The investigators also found that the lesion borders were clearly demarcated 60 seconds after contrast media injection, suggesting sufficient perfusion. The intensity-versus-time data for the contrast-enhanced lesion indicated a rapid initial uptake of gadolinium and a gradual washout over the next several minutes. Direct visual comparison of right ventricular lesions on gross examination and those derived on contrast enhanced MR imaging 10 minutes after ablation demonstrated similar lesion geometries. Lesion width and length measured on gross examinations and contrast enhanced MR imaging examinations correlated well (width: $6.7 \pm 0.5$ versus $7.1 \pm 0.9 \mathrm{~mm}, P<0.05$; length: $9.4 \pm 1.5$ versus $9.9 \pm 0.9 \mathrm{~mm}, P<0.05)$. Differential enhancement is based on the fractional distribution volumes of gadolinium chelates in 
normal and infarcted myocardium. Arheden et al. found in normal myocardium that gadolinium chelates could not penetrate the membrane of viable cells and therefore the enhancement was derived from the extracellular compartment. After ablation, myocardial cells lose their integrity that allows the diffusion of the contrast agent into the intracellular compartment resulting in regional hyperenhancement $[87,88]$.

Dickfeld et al. [6] described the characteristics of radiofrequency ablation of gadolinium-enhanced MR imaging. They found that 1) gadolinium enhanced MR imaging displayed four distinct phases of enhancement: signal void at 1 min, peripheral enhancement at 15-45 min, complete enhancement at $85 \mathrm{~min}$, and loss of enhancement at $600 \mathrm{~min}$; 2) the size of radiofrequency lesions, transmural extent, and gaps between the lesions could be adequately assessed on dynamic and delayed MR images and 3) the appearance of radiofrequency lesions on contrast enhanced MR imaging was similar over a wide range of applied energy.

A few studies have examined the histology of human atrial myocardium after atrial fibrillation ablation procedures. Deneke et al. [89] sampled 59 lesions at the time of intraoperative cooled tip RF catheter ablation and found lack of transmurality in $25 \%$ of all lesions. Accord et al. [90] reported the histological findings in 3 patients who died 2 to 22 days after intraoperative epicardial microwave ablation for pulmonary vein isolation. At autopsy, only 3 of 13 specimens from these patients showed transmural lesions. Kowalski et al. [91] described the histopathologic and electrophysiological findings in 12 patients with recurrence of atrial fibrillation after $8 \pm 11$ month after pulmonary vein isolation, which underwent a subsequent surgical maze procedure. The most common evidence of injury was endocardial thickening in 21 specimens (95\%), fibrous scar in 18 specimens (82\%), and nuclear pyknosis in 16 specimens (73\%). The histological findings show that nontransmural ablation can produce a dynamic cellular substrate with features of reversible injury.

In an experimental study, Saeed et al. [14] used first pass perfusion and delayed contrast enhanced MR imaging for characterizing the effects of thermal ablation on the kidney (Figure 1 and 2). On both sequences, normal renal tissue was enhanced, but the ablated core was not. The ablated core appeared as wedge-shaped zone after administration of Gd-DTPA. These hypoenhanced wedge-shaped zones are most likely resulted from the destruction of blood vessels by the heat. Figure 4 shows macroscopic and microscopic changes in the ablated core and peri-ablated zone after thermal ablation. In gross specimens, three distinct zones were observed, namely white core (coagulation zone), red band (peri-ablated zone) and normal renal tissue. The peri-ablated zone was invaded by inflammatory cells and showed evidence of edema and damaged blood vessels. Similar pattern of MR enhancement was observed in ablated liver and prostate tumors [92-94]. Dromain et al. reported that the peri-ablated thin zone presented at two months in $32 \%$ of the total radiofrequency ablated lesion [93]. They also found that the peri-ablated thin zone was better visualized on delayed contrast enhanced than first pass perfusion images. They also indicated that the enhanced peri-ablated zone should not be misread as peripheral tumor re-growth because residual or recurrent tumors had irregular and thicker zone. Sironi et al. [95] studied 31 patients with hepatocellular carcinomas treated with RF ablation. They found that first pass perfusion and $\mathrm{T}_{2}-$ weighted MR sequences were more effective than computed tomography in showing the recurrence.
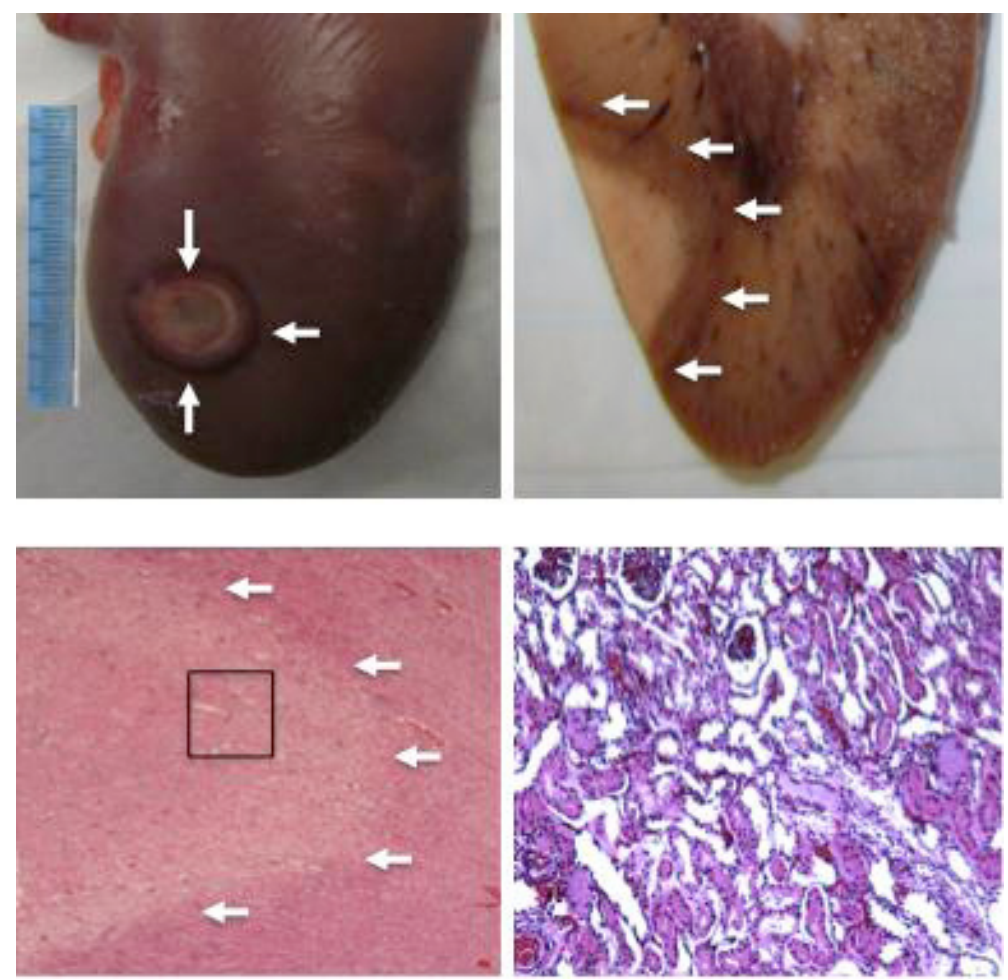

Figure 4: Macroscopic and microscopic sections show the ablated core and peri-ablated zone after thermal ablation (arrows). The H\&E stained tissue (bottom sections 10X and 100X; the box)) shows the damage of the nephrons, vascular obstruction and interstitial edema. These vascular and cellular changes attributed to the perfusion deficit seen on dynamic and delayed contrast enhanced MRI [14] 
Clinical studies showed the enhancement of the peri-ablated ablated soft tissues in the prostate, pancreas and lungs [96-98]. These findings were confirmed experimentally. Figure 5 shows the correlation between a contrast enhanced MR image and macroscopic section of the ablated soft tissue; such as the kidney. In the bones (femur and lumber vertebrate), contrast enhanced MR images provided no enhancement of the bones, but of the adjacent soft tissue (Figure 6 and 7) [99-101].
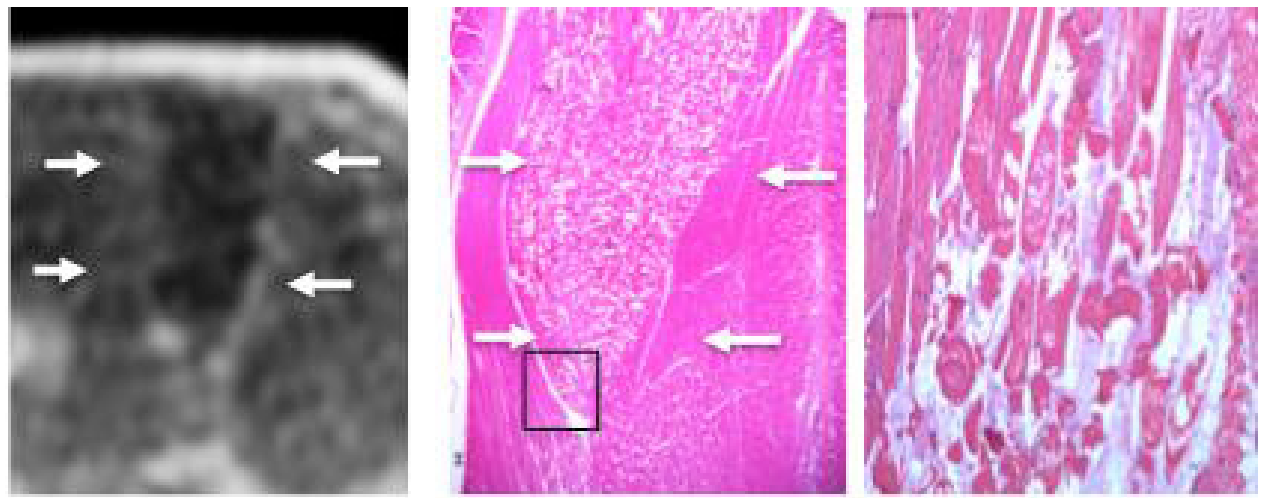

Figure 5: Left: Sagittal T1-weighted MR image of ablated muscles acquired one hour after thermal ablation. Gd-DTPA (0.15 mmol/ $\mathrm{kg}$ ) was intravenously injected to delineate the ablated tissue. Note that the peri-ablated zone was enhanced, but not the core of ablated region (arrows); Center: Low magnification section (10X) shows the ablated triangular tissue surrounded by normal tissue (arrows); Right: High magnification section (40X) of the box in the center shows the expansion of interstational compartment (light stained spaces) in the ablated tissue on the cost of the shrinkage of the muscles [99]

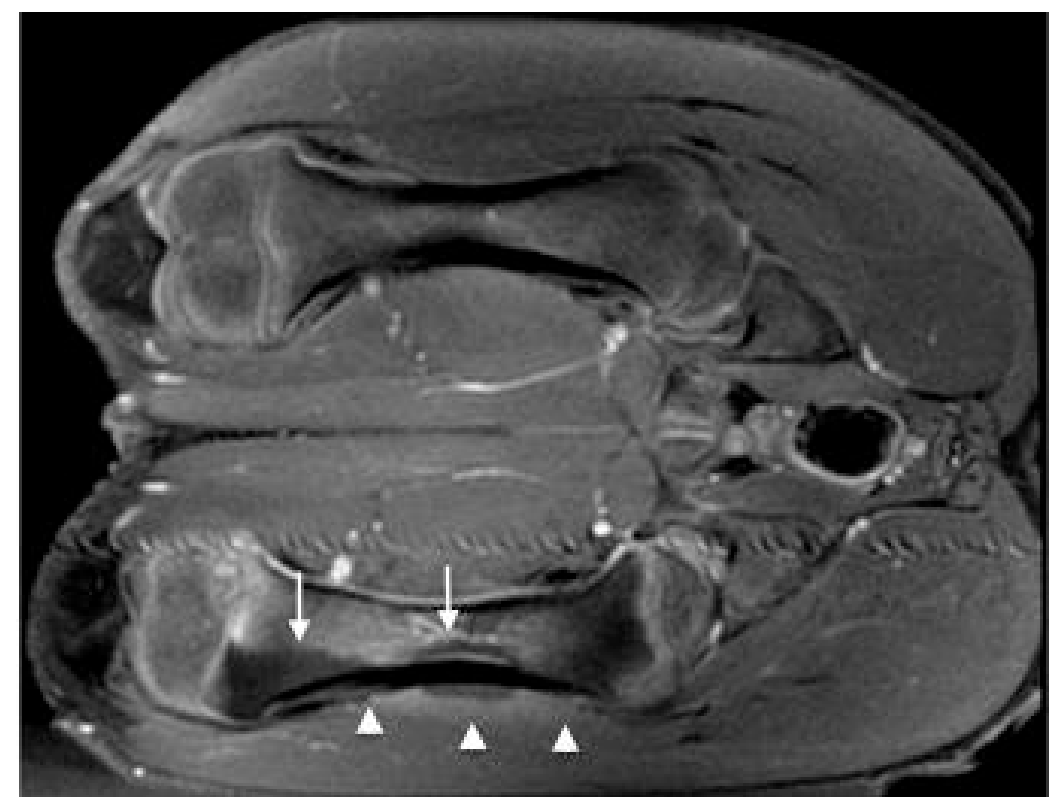

Figure 6: Coronal view of the two lesions (arrows) in the femur one hour after thermal ablation in swine model. The upper femur served as control. This T1-weighted fast spin echo image was acquired $10 \mathrm{~min}$ after administration of 0.15 $\mathrm{mmol} / \mathrm{kg} \mathrm{Gd}$-DTPA and shows the moderate enhancement of the adjacent muscles (arrowheads), but not the bone [100]
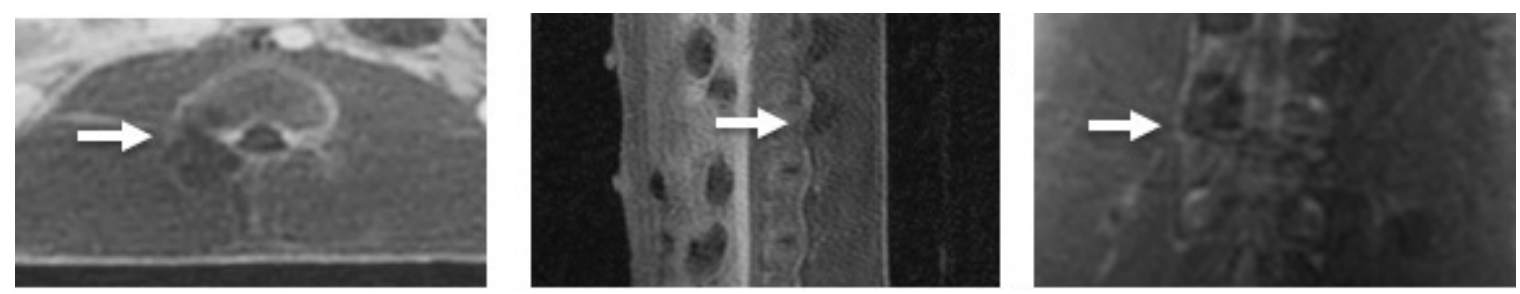

Figure 7: Left: Axial T1-weighted MR image of ablated lumber facet joint acquired one hour after thermal ablation (arrows). Gd-DTPA (0.15 $\mathrm{mmol} / \mathrm{kg}$ ) was intravenously injected to delineate the ablated tissue. Again, the peri-ablated zone was enhanced, but not the core of ablated region; Center: Sagittal view shows the left ablated facet joint (arrow); Right: Coronal view shows of the enhanced rim of the ablated facet joint [99]

\section{MR Contrast Media during Ablations}

Most previous clinical studies showed that contrast enhanced MR imaging was involved in pre-interventional planning and followup but not in the ablation process. Intraoperative MR contrast media, however, are necessary because: 1) it allows positioning of the ablation device within the lesion, 2) it provides assessment of the distribution of ablating chemical agents with similar molecular weight [102-105]. 
Delivery of ablating therapeutic agents such as ethanol, ethanolamine oleate, acetic acid or chemotherapeutic directly into a pathologic lesion during interventions is considered to be an effective treatment for a wide range of diseases [104-109], including liver tumors [110] and benign prostatic hyperplasia [111]. Among the various ablative agents, absolute ethanol is widely used [112]. Alcohol ablation has been used as an alternative to open heart surgery in hypertrophic obstructive cardiomyopathy. During ablation, injected ablation chemicals produce no differential enhancement. Therefore, investigators mixed ethanol with gadolinium chelates to demonstrate the spatial diffusion of the mixture and localization of the necrosis $[109,113,114]$. Van Dockum et al. [113] visualized regional hyperenhancement in the basal interventricular septum in all treated patients after mixing MR contrast media with ethanol. Furthermore, they were able to measure infarction size on contrast enhanced MR imaging (20 $\pm 9 \mathrm{~g}$, corresponding to $10 \pm 5 \%$ and $31 \pm 16 \%$ of left ventricle and septal mass, respectively). Nanz et al. [115] found that the mixture of gadolinium chelates and ethanol had no risk for interventional procedures. The enhancement by gadolinium chelates in ethanol versus aqueous solutions was similar on spoiled gradient-echo MR imaging.

Magnetic heating using iron oxide particles $\left(\mathrm{Fe}_{3} \mathrm{O}_{4}\right)$ is another approach in tumor ablation [5,116-120]. The heating of iron oxide particles subjected to an alternating magnetic field is caused by a combination of hysteresis loss and Neel-Brownian relaxation. Cellular coagulation was achieved when temperatures exceed $42{ }^{\circ} \mathrm{C}$ for over 30 minutes [121]. Gupta et al. found that the extent of rise in temperature depended upon magnetic properties of the particles, magnetic field strength, frequency of oscillation, and cooling capacity of the blood flow in the tumor site [122]. This approach offers a selective detection and refined tuning of the degree of energy deposition at the target.

Other investigators used radiofrequency ablation, which included insertion of a catheter into the tumor through the skin to induce focal coagulative necrosis in targeted tissues. The method was based on producing a radiofrequency of $200-1200 \mathrm{kHz}$ or temperature of $60-100{ }^{\circ} \mathrm{C}[123,124]$. MR contrast media played a crucial role in confirming the success of radiofrequency ablation in the lung and liver tumors [125-128]. Gadophrin 2, a necrosis specific MR contrast medium, showed great potential for delineating ablated liver tissue using radiofrequency $[67,68]$.

Similarly, percutaneous microwave ablation is another effective treatment option for patients who are unfit to undergo surgical resection $[129,130]$. The electromagnetic field creates rapid and homogeneous heating on tissue and subsequently coagulative necrosis. This technique has been used in the lung, kidney, bone, pancreas, adrenal glands, chest wall, liver, brain, and prostate [131]. Dong B, et al. found that gadolinium enhanced MR imaging was a more sensitive method than contrast enhanced CT for evaluating the degree of tumor coagulative necrosis in hepatocellular carcinoma after microwave coagulation therapy [132].

Focused ultrasound ablation has been successfully used in treating patients with various types of tumors [133-136]. Currently two complementary approaches are used to assess coagulative necrosis [137]. The first approach utilizes temperature sensitive MR parameters (e.g., $T_{1}$ relaxation time, water diffusion, and water proton chemical shift) to noninvasively record the temperature distribution at the treatment site during ablation. The second approach uses contrast enhanced $M R$ imaging [75,138]. Recent innovations in the field of thermal ablation procedures and real-time imaging have led to the development of MR-guided high intensity focused ultrasound (MRg-HIFU). This noninvasive technique targets tumor by focusing ultrasound waves to induce lethal temperatures [139]. The current clinical applications of this technique are in the following diseases: uterine fibrosis, bone tumors (osteoid osteomas and primary malignancy), peripheral and central neurological-diseases (peripheral nerves and essential tremor), and abdominal tumors (renal and hepatic). Experimental studies showed that MR contrast media were crucial for confirming and sizing necrotic tissues $[14,100,101]$. These studies also indicated that gadolinium chelates were useful for detecting collateral damage caused by the extra heat derived from targeted tissues or ablation device missing the target.

\section{Limitations of MR Contrast Media}

It has been noted that the usage of gadolinium chelates is restricted in cases of renal disease and allergy due to the dissociation of the gadolinium from the chelates [140]. Investigators found gadolinium as insoluble salts in bones, liver and spleen. On the other hand, another recent study indicated that there was no evidence of gadolinium dissociation in vivo [141]. In an in vitro study, investigators found that the dissociation rate of gadolinium from Gd-DTPA was very low even when the contrast agent was dissolved in ethanol, and the admixture produced an increase of signal that was sufficient for reliable visualization at $0.5 \mathrm{~T}$ and 1.5T [115]. It appears that the degree of gadolinium dissociation varies and depends on the structure of the chelates. For example, greatest dissociation of gadolinium ions is in nonionic linear chelates (DTPA-BMA) compared to ionic linear (DTPA) and macrocyclic (DOTA, HP-DO3A) [142,143].

The major side effects of free gadolinium and its chelates are: 1) the ionic radius of gadolinium is close to that of calcium which causes blockage of the calcium channels and inhibition of calcium-dependent physiological processes [144] and 2) the presence of free gadolinium in the plasma is associated with the development of nephrogenic systemic fibrosis disease [145-147]. Nephrogenic systemic fibrosis, also known as nephrogenic fibrosing dermopathy, is a fibrotic disease of the skin and internal organs reminiscent but distinct from scleroderma or scleromyxedema. Evidence for a link between nephrogenic systemic fibrosis and gadolinium was first described in a case series of 13 patients, all of whom developed nephrogenic systemic fibrosis after being exposed to gadolinium [148]. The chelated forms of the less stable gadolinium chelates might have a significant role but it appears that gradual release of the dissociated gadolinium is pivotal in the development of nephrogenic systemic fibrosis [149]. The subsequential 
cleanup of the necrotic tissue by macrophages could also lead to gadolinium redistribution in healthy tissues. In current clinical practice, however, risks in regard to the combined use of gadolinium chelates and hyperthermia were minimized by performing the contrast enhanced MR imaging days before ablation, ensuring clearance of gadolinium at the time of ablation [150]. Care must be taken with the use of proton resonance frequency shift-based MR thermometry in combination with gadolinium chelates because it disturbs local magnetic field during MR thermometry, leading to errors in temperature calculations. It should also be noted that gadolinium chelates cannot distinguish viable tumor cells from granulation tissue or viable tumor from reactive tissue at the peri-ablated zone.

Iron oxide particles have other types of limitations namely biological aggregation in vivo, which cause poor distribution, reduced heating capability [151,152] and possibly microvascular obstruction. The migration of the particles from tumors leads to false metastasis.

The development of molecular MR contrast medium to noninvasively detect fibrotic tissue is needed to optimize a personalized therapeutic strategy. $\mathrm{T}_{1}$ and $\mathrm{T}_{2}$ sequences with $\mathrm{MR}$ contrast media are useful for detecting and monitoring the evolution of fibrotic tissue after ablation [153,154]. The major obstacles in using MR contrast media at the present time are the dissociation of gadolinium from the chelates and nephrogenic systemic fibrosis. The development of targeted contrast medium with stable chelates will allow the use of MR contrast in: 1) Pre-interventional planning for defining the lesion for thermal ablation therapy and distinguishing penumbra and necrosis, 2) During intervention for targeting the lesion that involves placement of an applicator into the target tissue and 3) Monitoring the effects of therapy on defined volume of the scar after the ablation, where delayed contrast enhanced MR imaging provides appropriate restaging of ablated tissue.

\section{Conclusion}

MR contrast media provide vital information on microvascular perfusion/permeability, blood volume, extracellular volume, and tissue viability before and after ablation therapies. Iron oxide particles have dual roles in tissue ablation: 1) detecting lesions before, during and after ablation and 2) enhancing lesion temperature during thermal ablation. Safe, stable and thermal sensitive MR contrast media are needed to broaden the applications of MR contrast media in ablation therapies. The development of targeted molecular MR contrast media could help in optimizing a personalized therapeutic strategy. The provision of characteristics of preduring and post-ablation tissue characteristics with MR contras media might be helpful in complex ablation procedures.

\section{References}

1. Goldberg SN, Gazelle GS, Mueller PR (2000) Thermal ablation therapy for focal malignancy: a unified approach to underlying principles, techniques, and diagnostic imaging guidance. AJR Am J Roentgenol 174: 323-31.

2. Chang IA (2010) Considerations for Thermal Injury Analysis for RF Ablation Devices. Open Biomed Eng J 4: 3-12.

3. Saeed M, Wilson M (2012) Value of MR contrast media in image-guided body interventions. World J Radiol 4: 1-12.

4. Maier-Hauff K, Ulrich F, Nestler D, Niehoff H, Wust P, et al. (2011) Efficacy and safety of intratumoral thermotherapy using magnetic iron-oxide nanoparticles combined with external beam radiotherapy on patients with recurrent glioblastoma multiforme. J Neurooncol 103: 317-24.

5. Chu KF, Dupuy DE (2014) Thermal ablation of tumours: biological mechanisms and advances in therapy. Nat Rev Cancer 14: 199-208.

6. Dickfeld T, Kato R, Zviman M, Lai S, Meininger G, et al. (2006) Characterization of radiofrequency ablation lesions with gadolinium-enhanced cardiovascular magnetic resonance imaging. J Am Coll Cardiol 47: 370-8.

7. McGann CJ, Kholmovski E, Blauer J, Vijayakumar S, Gloschat C, et al. (2010) Acute injury immediately post atrial fibrillation ablation defined by MRI. J Cardiovasc Magn Reson 12: 10.1186/1532-429X-12-S1-M1.

8. McGann CJ, Kholmovski EG, Oakes RS, Blauer JJ, Daccarett M, et al. (2008) New Magnetic Resonance Imaging-Based Method for Defining the Extent of Left Atrial Wall Injury After the Ablation of Atrial Fibrillation. J Am Coll Cardiol 52: 1263-71.

9. Badger TJ, Oakes RS, Daccarett M, Burgon NS, Akoum N, et al. (2009) Temporal left atrial lesion formation after ablation of atrial fibrillation. Heart Rhythm 6: 161-8.

10. Henk CB, Higgins CB, Saeed M (2005) Endovascular interventional MRI. J Magn Reson Imaging 22: 451-60.

11. Saeed M, Saloner D, Weber O, Martin A, Henk C, et al. (2005) MRI in guiding and assessing intramyocardial therapy. Eur Radiol 15: 851-63.

12. Campbell-Washburn AE, Faranesh AZ, Lederman RJ, Hansen MS (2015) Magnetic Resonance Sequences and Rapid Acquisition for MR-Guided Interventions. Magn Reson Imaging Clin N Am 23: 669-79.

13. Mazal JR, Rogers T, Schenke WH, Faranesh AZ, Hansen M, et al. (2016) Interventional-Cardiovascular MR: Role of the Interventional MR Technologist. Radiol Technol 87: 261-70.

14. Saeed M, Krug R, Do L, Hetts SW, Wilson MW (2016) Renal ablation using magnetic resonance-guided high intensity focused ultrasound: Magnetic resonance imaging and histopathology assessment. World J Radiol 8: 298-307.

15. Ertürk MA, Hegde SS, Bottomley PA (2016) Radiofrequency Ablation, MR Thermometry, and High-Spatial-Resolution MR Parametric Imaging with a Single, Minimally Invasive Device. Radiology 0: 10.1148/radiol.2016151447.

16. Ramanathan R, Leveillee RJ (2010) Ablative therapies for renal tumors. Ther Adv Urol 2: 51-68.

17. Dewire J, Calkins H (2013) Update on atrial fibrillation catheter ablation technologies and techniques. Nat Rev Cardiol 10: 599-612.

18. Murphy KP, Maher MM, O’Connor OJ (2015) Abdominal Ablation Techniques. AJR Am J Roentgenol 204: W495-W502.

19. Tatli S, Tapan U, Morrison PR, Silverman SG (2012) Radiofrequency ablation: technique and clinical applications. Diagn Interv Radiol 18: 508-16.

20. Saeed M, Wendland MF, Watzinger N, Akbari H, Higgins CB (2000) MR contrast media for myocardial viability, microvascular integrity and perfusion. Eur J Radiol 34: 179-95. 
21. Saeed M, Wendland MF, Yu KK, Higgins CB (1992) Delineation of acute myocardial infarction with dysprosium DTPA-BMA: Influence of dose of magnetic susceptibility contrast medium. J Am Coll Cardiol 20: 1634-41.

22. Saeed M, Wendland MF, Yu KK, Li HT, Higgins CB (1993) Dual effects of gadodiamide injection in depiction of the region of myocardial ischemia. J Magn Reson Imaging 3: 21-9.

23. Saeed M, Wendland MF, Engelbrecht M, Sakuma H, Higgins CB (1998) Value of blood pool contrast agents in magnetic resonance angiography of the pelvis and lower extremities. Eur Radiol 8: 1047-53.

24. Cyran CC, Sennino B, Fu Y, Rogut V, Shames DM, et al. (2012) Permeability to macromolecular contrast media quantified by dynamic MRI correlates with tumor tissue assays of vascular endothelial growth factor (VEGF). Eur J Radiol 81: 891-6.

25. Kholmovski EG, Vijayakumar S, Ranjan R, Blauer J, Volland N, et al. (2012) Application of blood pool contrast agent to visualize atrial lesion formation during RF ablation procedure. Proc. Intl. Soc. Mag. Reson. Med 20: 2929.

26. Solomon SB, Bohlman ME, Choti MA (2002) Percutaneous Gadolinium Injection under MR Guidance to Mark Target for CT-guided Radiofrequency Ablation. J Vasc Interv Radiol 13: 419-21

27. König CW, Schott UG, Pereira PL, Trübenbach J, Schneider W, et al. (2002) MR-guided lumbar sympathicolysis. Eur Radiol 12: 1388 -93.

28. Parodi JC, Ferreira LM (2000) Gadolinium-based contrast: an alternative contrast agent for endovascular interventions. Ann Vasc Surg 14: 480-3.

29. Schwitter J, Saeed M, Wendland MF, Derugin N, Canet E, et al. (1997) Influence of severity of myocardial injury on distribution of macromolecules: extravascular versus intravascular gadolinium-based magnetic resonance contrast agents. J Am Coll Cardiol 30: 1086-94.

30. Kuwatsuru R, Shames DM, Mühler A, Mintorovitch J, Vexler V, et al. (1993) Quantification of tissue plasma volume in the rat by contrast-enhanced magnetic resonance imaging. Magn Reson Med 30: 76-81.

31. Bartolozzi C, Lencioni R, Caramella D, Mazzeo S, Ciancia EM (1994) Treatment of hepatocellular carcinoma with percutaneous ethanol injection: evaluation with contrast-enhanced MR imaging. AJR Am J Roentgenol 162: 827-31.

32. Bartolozzi C, Lencioni R, Caramella D, Falaschi F, Cioni R, et al. (1994) Hepatocellular carcinoma: CT and MR features after transcatheter arterial embolization and percutaneous ethanol injection. Radiology 191: 123-8.

33. Wilson MW, Fidelman N, Weber OM, Martin AJ, Gordon RL, et al. (2003) Experimental renal artery embolization in a combined MR imaging/angiographic unit. J Vasc Interv Radiol 14: 1169-75.

34. Grobner T (2006) Gadolinium--a specific trigger for the development of nephrogenic fibrosing dermopathy and nephrogenic systemic fibrosis? Nephrol Dial Transplant 21: 1104-8

35. Saeed M, Wendland MF, Masui T, Yu KK, Li JJ, et al. (1993) Dual mechanisms for change in myocardial signal intensity by means of a single MR contrast medium: dependence on concentration and pulse sequence. Radiology 186: 175-82.

36. Yu KK, Saeed M, Wendland MF, Derugin N, Cavagna FM, et al.. (1992) Real-Time Dynamics of an Extravascular Magnetic Resonance Contrast Medium in Acutely Infarcted Myocardium Using Inversion Recovery and Gradient-Recalled Echo-Planar Imaging. Investigative Radiology 27: $927-34$.

37. Ruehm SG, Corot C, Vogt P, Kolb S, Debatin JF (2001) Magnetic resonance imaging of atherosclerotic plaque with ultrasmall superparamagnetic particles of iron oxide in hyperlipidemic rabbits. Circulation 103: 415-22.

38. John R, Chaney EJ, Boppart SA (2010) Dynamics of Magnetic Nanoparticle-Based Contrast Agents in Tissues Tracked Using Magnetomotive Optical Coherence Tomography. IEEE Journal of Selected Topics in Quantum Electronics 16: 691-7.

39. Simon GH, Bauer J, Saborovski O, Fu Y, Corot C, et al. (2006) T1 and T2 relaxivity of intracellular and extracellular USPIO at 1.5T and 3T clinical MR scanning. Eur Radiol 16: 738-45.

40. Albanese A, Tang PS, Chan WC (2012) The Effect of Nanoparticle Size, Shape, and Surface Chemistry on Biological Systems. Annu Rev Biomed Eng 14: 1-16.

41. Thorek DL, Chen AK, Czupryna J, Tsourkas A (2006) Superparamagnetic Iron Oxide Nanoparticle Probes for Molecular Imaging. Ann Biomed Eng 34: 23-38.

42. Couvreur P, Vauthier C (2006) Nanotechnology: Intelligent Design to Treat Complex Disease. Pharm Res 23: 1417-50.

43. Longmire M, Choyke PL, Kobayashi H (2008) Clearance Properties of Nano-sized Particles and Molecules as Imaging Agents: Considerations and Caveats. Nanomedicine 3: 703-17.

44. Yilmaz A, Dengler MA, van der Kuip H, Yildiz H, Rösch S, et al. (2013) Imaging of myocardial infarction using ultrasmall superparamagnetic iron oxide nanoparticles: a human study using a multi-parametric cardiovascular magnetic resonance imaging approach. Eur Heart J 34: 462-75.

45. Kuhlpeter R, Dahnke H, Matuszewski L, Persigehl T, von Wallbrunn A, et al. (2007) R2 and R2* mapping for sensing cell-bound superparamagnetic nanoparticles: in vitro and murine in vivo testing. Radiology 245: 449-57.

46. Liong M, Lu J, Kovochich M, Xia T, Ruehm SG, et al. (2008) Multifunctional Inorganic Nanoparticles for Imaging, Targeting, and Drug Delivery. ACS Nano 2: $889-96$.

47. Gharagouzloo CA, McMahon PN, Sridhar S (2015) Quantitative contrast-enhanced MRI with superparamagnetic nanoparticles using ultrashort time-to-echo pulse sequences. Magn Reson Med 74: 431-41.

48. Alexiou C, Jurgons R, Seliger C, Iro H (2006) Medical Applications of Magnetic Nanoparticles. J Nanosci Nanotechnol 6: 2762-8.

49. Higgins CB, Saeed M, Wendland M (1991) Contrast enhancement for the myocardium. Magn Reson Med 22: $347-53$.

50. Higgins CB, Saeed M, Wendland MF, Sakuma H (1994) Role of magnetic resonance contrast media in ischemic myocardial disease. Invest Radiol 29: S294-6.

51. Laurent S, Forge D, Port M, Roch A, Robic C, et al. (2008) Magnetic Iron Oxide Nanoparticles: Synthesis, Stabilization, Vectorization, Physicochemical Characterizations, and Biological Applications. Chem Rev 108: 2064-110

52. Chertok B, Moffat BA, David AE, Yu F, Bergemann C, et al. (2008) Iron oxide nanoparticles as a drug delivery vehicle for MRI monitored magnetic targeting of brain tumors. Biomaterials 29: 487-96.

53. Na HB, Song IC, Hyeon T (2009) Inorganic Nanoparticles for MRI Contrast Agents. Advan Materials 21: $2133-48$.

54. Wang L, Zhong X, Qian W, Huang J, Cao Z, et al. (2014) Ultrashort Echo Time (UTE) Imaging of Receptor Targeted Magnetic Iron Oxide Nanoparticles in Mouse Tumor Models. J magn reson imaging 40: 1071-81.

55. Sun C, Lee JS, Zhang M (2008) Magnetic nanoparticles in MR imaging and drug delivery. Adv Drug Deliv Rev 60: $1252-65$.

56. Arruebo M, Fernández-Pacheco R, Ibarra MR, Santamaría J (2007) Magnetic nanoparticles for drug delivery. Nano Today 2: 22-32. 
57. Neuwelt EA, Várallyay P, Bagó AG, Muldoon LL, Nesbit G, et al. (2004) Imaging of iron oxide nanoparticles by MR and light microscopy in patients with malignant brain tumours. Neuropathol Appl Neurobiol 30: 456-71.

58. Saeed M, Higgins CB, Geschwind JF, Wendland MF (2000) T1-relaxation kinetics of extracellular, intracellular and intravascular MR contrast agents in normal and acutely reperfused infarcted myocardium using echo-planar MR imaging. Eur Radiol 10: 310-8.

59. Saeed M, Wendland MF, Higgins CB (2000) Blood pool MR contrast agents for cardiovascular imaging. J Magn Reson Imaging 12: 890-8.

60. Essig M, Shiroishi MS, Nguyen TB, Saake M, Provenzale JM, et al. (2013) Perfusion MRI: The Five Most Frequently Asked Technical Questions. AJR Am J Roentgenol 200: 24-34.

61. Saeed M, Van TA, Krug R, Hetts SW, Wilson MW (2015) Cardiac MR imaging: current status and future direction. Cardiovasc Diagn Ther 5: 290-310.

62. Kim MJ, Kim JH, Chung JJ, Park MS, Lim JS, et al. (2003) Focal Hepatic Lesions: Detection and Characterization with Combination Gadolinium- and Superparamagnetic Iron Oxide-enhanced MR Imaging. Radiol 228: 719-26.

63. Kim SK, Lim HK, Kim YH, Lee WJ, Lee SJ, et al. (2003) Hepatocellular Carcinoma Treated with Radio-frequency Ablation: Spectrum of Imaging Findings. RadioGraphics 23: 107-21.

64. Bartolozzi C, Donati F, Cioni D, Procacci C, Morana G, et al. (2004) Detection of colorectal liver metastases: a prospective multicenter trial comparing unenhanced MRI, MnDPDP-enhanced MRI, and spiral CT. Eur Radiol 14: 14-20.

65. Ni Y, Marchal G, van Damme B, van Hecke P, Michiels J, et al. (1992) Magnetic Resonance Imaging, Microangiography, and Histology in a Rat Model of Primary Liver Cancer. Invest Radiol 27: 689-97.

66. Joarder R, de Jode M, Lamb GA, Gedroyc WM (2001) The value of MnDPDP enhancement during MR guided laser interstitial thermoablation of liver tumors. J Magn Reson Imaging 13: 37-41.

67. Ni Y, Mulier S, Miao Y, Michel L, Marchal G (2005) A review of the general aspects of radiofrequency ablation. Abdom Imaging 30: 381-400.

68. Ni Y, Chen F, Mulier S, Sun X, Yu J, et al. (2006) Magnetic resonance imaging after radiofrequency ablation in a rodent model of liver tumor: tissue characterization using a novel necrosis-avid contrast agent. Eur Radiol 16: 1031-40.

69. Tomalia DA, Reyna LA, Svenson S (2007) Dendrimers as multi-purpose nanodevices for oncology drug delivery and diagnostic imaging. Biochem Soc Trans 35: 61-7.

70. Kobayashi H, Kawamoto S, Sakai Y, Choyke PL, Star RA, et al. (2004) Lymphatic Drainage Imaging of Breast Cancer in Mice by Micro-Magnetic Resonance Lymphangiography Using a Nano-Size Paramagnetic Contrast Agent. J Natl Cancer Inst 96: 703-8.

71. Damjanov I (2002) Pathology of the Liver. Mod Pathol 15: 278.

72. Di Martino M, Marin D, Guerrisi A, Baski M, Galati F, et al. (2010) Intraindividual Comparison of Gadoxetate Disodium-enhanced MR Imaging and 64-Section Multidetector CT in the Detection of Hepatocellular Carcinoma in Patients with Cirrhosis. Radiology 256: 806-16.

73. Ringe KI, Husarik DB, Sirlin CB, Merkle EM (2010) Gadoxetate Disodium-Enhanced MRI of the Liver: Part 1, Protocol Optimization and Lesion Appearance in the Noncirrhotic Liver. AJR Am J Roentgenol 195: 13-28.

74. Vogl TJ, Kümmel S, Hammerstingl R, Schellenbeck M, Schumacher G, et al. (1996) Liver tumors: comparison of MR imaging with Gd-EOB-DTPA and GdDTPA. Radiology 200: 59-67.

75. Chen L, Bouley D, Yuh E, D’Arceuil H, Butts K (1999) Study of focused ultrasound tissue damage using MRI and histology. J Magn Reson Imaging 10: 146-53. 76. Chen J, Daniel BL, Diederich CJ, Bouley DM, van den Bosch MA, et al. (2008) Monitoring prostate thermal therapy with diffusion-weighted MRI. Magn Reson Med 59: 1365-72.

77. Josan S, Bouley DM, van den Bosch M, Daniel BL, Butts Pauly K (2009) MRI-guided cryoablation: In vivo assessment of focal canine prostate cryolesions. J Magn Reson Imaging 30: 169-76.

78. Lang P, Wendland MF, Saeed M, Gindele A, Rosenau W, et al. (1998) Osteogenic sarcoma: noninvasive in vivo assessment of tumor necrosis with diffusionweighted MR imaging. Radiology 206: 227-35.

79. Goldberg SN, Gazelle GS, Compton CC, Mueller PR, Tanabe KK (2000) Treatment of intrahepatic malignancy with radiofrequency ablation: radiologicpathologic correlation. Cancer 88: 2452-63.

80. Babu-Narayan SV, Goktekin O, Moon JC, Broberg CS, Pantely GA, et al. (2005) Late gadolinium enhancement cardiovascular magnetic resonance of the systemic right ventricle in adults with previous atrial redirection surgery for transposition of the great arteries. Circulation 111: 2091-8.

81. Nazarian S, Bluemke DA, Lardo AC, Zviman MM, Watkins SP, et al. (2005) Magnetic Resonance Assessment of the Substrate for Inducible Ventricular Tachycardia in Nonischemic Cardiomyopathy. Circulation 112: 2821-5.

82. Dickfeld T, Tian J, Ahmad G, Jimenez A, Turgeman A, et al. (2011) MRI-Guided Ventricular Tachycardia Ablation: Integration of Late Gadolinium-Enhanced 3D Scar in Patients With Implantable Cardioverter-Defibrillators. Circ Arrhythm Electrophysiol 4: 172-84.

83. Steinberg BA, Hammill BG, Daubert JP, Bahnson TD, Douglas PS, et al. (2014) Periprocedural imaging and outcomes after catheter ablation of atrial fibrillation. Heart 100: 1871-7.

84. McGann C, Kholmovski E, Blauer J, Vijayakumar S, Haslam T, et al. (2011) Dark Regions of No-Reflow on Late Gadolinium Enhancement Magnetic Resonance Imaging Result in Scar Formation After Atrial Fibrillation Ablation. J Am Coll Cardiol 58: 177-85.

85. Vergara GR, Vijayakumar S, Kholmovski EG, Blauer JJ, Guttman MA, et al. (2011) Real-time magnetic resonance imaging-guided radiofrequency atrial ablation and visualization of lesion formation at 3 Tesla. Heart Rhythm 8: 295-303.

86. Lardo AC, McVeigh ER, Jumrussirikul P, Berger RD, Calkins H, et al. (2000) Visualization and Temporal/Spatial Characterization of Cardiac Radiofrequency Ablation Lesions Using Magnetic Resonance Imaging. Circulation 102: 698-705.

87. Arheden H, Saeed M, Higgins CB, Gao DW, Bremerich J, et al. (1999) Measurement of the distribution volume of gadopentetate dimeglumine at echo-planar MR imaging to quantify myocardial infarction: comparison with 99mTc-DTPA autoradiography in rats. Radiology 211: 698-708.

88. Arheden H, Saeed M, Higgins CB, Gao DW, Ursell PC, et al. (2000) Reperfused rat myocardium subjected to various durations of ischemia: estimation of the distribution volume of contrast material with echo-planar MR imaging. Radiology 215: 520-8.

89. Deneke T, Khargi K, Müller KM, Lemke B, Mügge A, et al. (2005) Histopathology of intraoperatively induced linear radiofrequency ablation lesions in patients with chronic atrial fibrillation. Eur Heart J 26: 1797-803. 
90. Accord RE, van Suylen RJ, van Brakel TJ, Maessen JG (2005) Post-Mortem Histologic Evaluation of Microwave Lesions After Epicardial Pulmonary Vein Isolation for Atrial Fibrillation. Ann Thorac Surg 80: 881-7.

91. Kowalski M, Grimes MM, Perez FJ, Kenigsberg DN, Koneru J, et al. (2012) Histopathologic Characterization of Chronic Radiofrequency Ablation Lesions for Pulmonary Vein Isolation. J Am Coll Cardiol 59: 930-8.

92. Braga L, Guller U, Semelka RC (2005) Pre-, Peri-, and Posttreatment Imaging of Liver Lesions. Radiol Clin North Am 43: 915-27.

93. Dromain C, de Baere T, Elias D, Kuoch V, Ducreux M, et al. (2002) Hepatic tumors treated with percutaneous radio-frequency ablation: CT and MR imaging follow-up. Radiology 223: 255-62.

94. Djavan B, Zlotta AR, Susani M, Heinz G, Shariat S, et al. (1997) Transperineal radiofrequency interstitial tumor ablation of the prostate: correlation of magnetic resonance imaging with histopathologic examination. Urology 50: 986-92.

95. Sironi S, Livraghi T, Meloni F, De Cobelli F, Ferrero C, et al. (1999) Small hepatocellular carcinoma treated with percutaneous RF ablation: MR imaging followup. AJR Am J Roentgenol 173: 1225-9.

96. Merkle EM, Haaga JR, Duerk JL, Jacobs GH, Brambs HJ, et al. (1999) MR Imaging-guided Radio-frequency Thermal Ablation in the Pancreas in a Porcine Model with a Modified Clinical C-Arm System. Radiology 213: 461-7.

97. Miao Y, Ni Y, Bosmans H, Yu J, Vaninbroukx J, et al. (2001) Radiofrequency ablation for eradication of pulmonary tumor in rabbits. J Surg Res 99: 265-71.

98. Merkle ME, Shonk JR, Zheng L, Duerk JL, Lewin JS (2001) MR imaging-guided radiofrequency thermal ablation in the porcine brain at 0.2 T. Eur Radiol 11: 884-92.

99. Krug R, Do L, Rieke V, Wilson MW, Saeed M (2016) Evaluation of MRI protocols for the assessment of lumbar facet joints after MR-guided focused ultrasound treatment. J Ther Ultrasound 4: 1-9.

100. Bucknor MD, Rieke V, Do L, Majumdar S, Link TM, et al. (2014) MRI-guided high-intensity focused ultrasound ablation of bone: evaluation of acute findings with MR and CT imaging in a swine model. J Magn Reson Imaging 40: 1174-80.

101. Bucknor MD, Rieke V, Seo Y, Horvai AE, Hawkins RA, et al. (2015) Bone remodeling after MR imaging-guided high-intensity focused ultrasound ablation: evaluation with MR imaging, CT, Na(18)F-PET, and histopathologic examination in a swine model. Radiology 274: 387-94.

102. Lewin JS, Merkle EM, Duerk JL, Tarr RW (1999) Low-Flow Vascular Malformations in the Head and Neck: Safety and Feasibility of MR Imaging-guided Percutaneous Sclerotherapy--Preliminary Experience with 14 Procedures in Three Patients. Radiology 211: 566-70.

103. Dubois J, Soulez G, Oliva VL, Berthiaume MJ, Lapierre C, et al. (2001) Soft-Tissue Venous Malformations in Adult Patients: Imaging and Therapeutic Issues. Radiographics 21: 1519-31.

104. Hayashi N, Masumoto T, Okubo T, Abe O, Kaji N, et al. (2003) Hemangiomas in the Face and Extremities: MR-guided Sclerotherapy--Optimization with Monitoring of Signal Intensity Changes in Vivo. Radiology 226: 567-72.

105. Boll DT, Merkle EM, Lewin JS (2004) Low-Flow Vascular Malformations: MR-guided Percutaneous Sclerotherapy in Qualitative and Quantitative Assessment of Therapy and Outcome. Radiology 233: 376-84.

106. Nielsen CD, Spencer WH (2002) Role of Controlled Septal Infarct in Hypertrophic Obstructive Cardiomyopathy. Cardiol Rev 10: 108-18.

107. Kovacic JC, Muller D (2003) Hypertrophic cardiomyopathy: state-of-the-art review, with focus on the management of outflow obstruction. Intern Med J 33: 521-9.

108. Runge VM (2000) Safety of approved MR contrast media for intravenous injection. J Magn Reson Imaging 12: 205-13.

109. Friedman MA, Wood BJ (2003) Precipitation of Gadolinium and Ethanol during Nerve Block. J Vasc Interv Radiol 14: 394.

110. Garcea G, Lloyd TD, Aylott C, Maddern G, Berry DP (2003) The emergent role of focal liver ablation techniques in the treatment of primary and secondary liver tumours. Eur J Cancer 39: 2150-64.

111. Plante MK, Folsom JB, Zvara P (2004) Prostatic Tissue Ablation By Injection: A Literature Review. J Urol 172: 20-6.

112. Burrows PE, Mason KP (2004) Percutaneous Treatment of Low Flow Vascular Malformations. J Vasc Interv Radiol 15: 431-45.

113. van Dockum WG, ten Cate FJ, ten Berg JM, Beek AM, Twisk JW, et al. (2004) Myocardial infarction after percutaneous transluminal septal myocardial ablation in hypertrophic obstructive cardiomyopathy: evaluation by contrast-enhanced magnetic resonance imaging. J Am Coll Cardiol 43: 27-34.

114. van Dockum WG, Beek AM, ten Cate FJ, ten Berg JM, Bondarenko, et al. (2005) Early Onset and Progression of Left Ventricular Remodeling After Alcohol Septal Ablation in Hypertrophic Obstructive Cardiomyopathy. Circulation 111: 2503-8.

115. Nanz D, Andreisek G, Fröhlich JM, Weishaupt D, Treiber K, et al. (2006) Contrast Material-enhanced Visualization of the Ablation Medium for Magnetic Resonance- monitored Ethanol Injection Therapy: Imaging and Safety Aspects. J Vasc Interv Radiol 17: 95-102.

116. Caizer C (2014) Computational study on superparamagnetic hyperthermia with biocompatible SPIONs to destroy the cancer cells. Journal of Physics: Conference Series 521: 1-4.

117. Hurley KR, Ring HL, Etheridge M, Zhang J, Gao Z, et al. (2016) Predictable Heating and Positive MRI Contrast from a Mesoporous Silica-Coated Iron Oxide Nanoparticle. Mol Pharm 13: 2172-83.

118. Laurent S, Dutz S, Häfeli UO, Mahmoudi M (2011) Magnetic fluid hyperthermia: Focus on superparamagnetic iron oxide nanoparticles. Advances Colloid Interface Sci 166: 8-23.

119. Hilger I, Hiergeist R, Hergt R, Winnefeld K, Schubert H, et al. (2002) Thermal Ablation of Tumors Using Magnetic Nanoparticles: An In Vivo Feasibility Study. Invest Radiol 37: 580-6.

120. García-Jimeno S, Ortega-Palacios R, Cepeda-Rubio MFJ, Vera A, Salas LL, et al. (2012) Improved thermal ablation efficacy using magnetic nanoparticles: a study in tumor phantoms. Progress In Electromagnetics Research 128: 229-48.

121. Pankhurst QA, Connolly J, Jones SK, Dobson J (2003) Applications of magnetic nanoparticles in biomedicine. J Phys D: Appli Phys 36: R167.

122. Gupta AK, Gupta M (2005) Synthesis and surface engineering of iron oxide nanoparticles for biomedical applications. Biomaterials $26: 3995-4021$.

123. Cha C, DeMatteo RP, Blumgart LH (2002) Surgery and Ablative Therapy for Hepatocellular Carcinoma. J Clin Gastroenterol 35 : S130-7.

124. Rhim H, Goldberg SN, Dodd GD, Solbiati L, Lim HK, et al. (2001) Essential Techniques for Successful Radio-frequency Thermal Ablation of Malignant Hepatic Tumors. Radiographics 21: S17-39. 
125. Lee JM, Jin GY, Goldberg SN, Lee YC, Chung GH, et al. (2004) Percutaneous Radiofrequency Ablation for Inoperable Non--Small Cell Lung Cancer and Metastases: Preliminary Report. Radiology 230: 125-34.

126. Dupuy DE (2011) Image-guided Thermal Ablation of Lung Malignancies. Radiology 260: 633-55.

127. Howard JH, Tzeng CW, Smith JK, Eckhoff DE, Bynon JS, et al. (2008) Radiofrequency Ablation for Unresectable Tumors of the Liver. Am Surg 74: 594-601.

128. Wells SA, Hinshaw JL, Lubner MG, Ziemlewicz TJ, Brace CL, et al. (2015) Liver Ablation: Best Practice. Radiol Clin North Am 53: 933-71.

129. Belfiore G, Ronza F, Belfiore MP, Serao N, di Ronza G, et al. (2013) Patients' survival in lung malignancies treated by microwave ablation: our experience on 56 patients. Eur J Radiol 82: 177-81.

130. Simon CJ, Dupuy DE, Mayo-Smith WW (2005) Microwave Ablation: Principles and Applications. Radiographics 25: S69-83.

131. Ryan TP, Turner PF, Hamilton B (2010) Interstitial microwave transition from hyperthermia to ablation: Historical perspectives and current trends in thermal therapy. Int J Hyperthermia 26: 415-33.

132. Dong B, Liang P, Yu X, Su L, Yu D, et al. (2003) Percutaneous Sonographically Guided Microwave Coagulation Therapy for Hepatocellular Carcinoma: Results in 234 Patients. AJR Am J Roentgenol 180: 1547-55.

133. ter Haar G, Sinnett D, Rivens I (1989) High intensity focused ultrasound-a surgical technique for the treatment of discrete liver tumours. Phys Med Biol 34: 1743-50.

134. Cline HE, Hynynen K, Watkins RD, Adams WJ, Schenck JF, et al. (1995) Focused US system for MR imaging-guided tumor ablation. Radiology 194: 731-7.

135. Hynynen K, Freund WR, Cline HE, Chung AH, Watkins RD, et al. (1996) A clinical, noninvasive, MR imaging-monitored ultrasound surgery method. Radiographics 16: 185-95.

136. Gelet A, Chapelon JY, Margonari J, Theillere Y, Gorry F, et al. (1993) High-Intensity Focused Ultrasound Experimentation on Human Benign Prostatic Hypertrophy. European Urology 23: 44-7.

137. Graham SJ, Bronskill MJ, Henkelman RM (1998) Time and temperature dependence of MR parameters during thermal coagulation of ex vivo rabbit muscle. Magn Reson Med 39: 198-203.

138. McDannold, Hynynen K, Wolf D, Wolf G, Jolesz F (1998) MRI evaluation of thermal ablation of tumors with focused ultrasound. J Magn Reson Imaging 8: 91-100.

139. Kennedy JE (2005) High-intensity focused ultrasound in the treatment of solid tumours. Nat Rev Cancer 5: 321-7.

140. Laurent S, Elst LV, Copoix F, Muller RN (2001) Stability of MRI Paramagnetic Contrast Media: A Proton Relaxometric Protocol for Transmetallation Assessment. Invest Radiol 36: 115-22.

141. Hijnen NM, Elevelt A, Grüll H (2013) Stability and Trapping of Magnetic Resonance Imaging Contrast Agents During High-Intensity Focused Ultrasound Ablation Therapy. Invest Radiol 48: 517-24.

142. Frenzel T, Lengsfeld P, Schirmer H, Hutter J, Weinmann HJ (2008) Stability of gadolinium-based magnetic resonance imaging contrast agents in human serum at 37 degrees C. Invest Radiol 43: 817-28.

143. Aime S, Caravan P (2009) Biodistribution of gadolinium-based contrast agents, including gadolinium deposition. J Magn Reson Imaging 30: $1259-67$.

144. Kahakachchi CL, Moore DA (2010) Identification and characterization of gadolinium(iii) complexes in biological tissue extracts. Metallomics 2: 490-7.

145. Abraham JL, Thakral C (2008) Tissue distribution and kinetics of gadolinium and nephrogenic systemic fibrosis. Eur J Radiol. 66: 200-7.

146. Steger-Hartmann T, Hofmeister R, Ernst R, Pietsch H, Sieber MA, et al. (2010) A review of preclinical safety data for magnevist (gadopentetate dimeglumine) in the context of nephrogenic systemic fibrosis. Invest Radiol 45: 520-8.

147. Weinreb JC, Abu-Alfa AK (2009) Gadolinium-based contrast agents and nephrogenic systemic fibrosis: why did it happen and what have we learned? J Magn Reson Imaging 30: 1236-9.

148. Marckmann P, Skov L, Rossen K, Dupont A, Damholt MB, et al. (2006) Nephrogenic systemic fibrosis: suspected causative role of gadodiamide used for contrast-enhanced magnetic resonance imaging. J Am Soc Nephrol 17: 2359-62.

149. Idee JM, Fretellier N, Robic C, Corot C (2014) The role of gadolinium chelates in the mechanism of nephrogenic systemic fibrosis: A critical update. Crit Rev Toxicol 44: 895-913.

150. Voogt MJ, van Stralen M, Ikink ME, Deckers R, Vincken KL, et al. (2012) Targeted Vessel Ablation for More Efficient Magnetic Resonance-Guided HighIntensity Focused Ultrasound Ablation of Uterine Fibroids. Cardiovasc Intervent Radiol 35: 1205-10.

151. Roch A, Gossuin Y, Muller RN, Gillis P (2005) Superparamagnetic colloid suspensions: Water magnetic relaxation and clustering. J Magnetism Magnetic Mater 293: 532-9.

152. Etheridge ML, Hurley KR, Zhang J, Jeon S, Ring HL, et al. (2014) Accounting for biological aggregation in heating and imaging of magnetic nanoparticles. Technology 2: 214-28.

153. Bohnen S, Radunski UK, Lund GK, Kandolf R, Stehning C, et al. (2015) Performance of T1 and T2 Mapping Cardiovascular Magnetic Resonance to Detect Active Myocarditis in Patients With Recent-Onset Heart Failure. Circ Cardiovasc Imaging 8: e003073.

154. Saeed M, Hetts SW, Liang A, Wilson MW (2016) Coronary Embolization and Myocardial Microinfarction: MR Imaging and Histopathologic Characterization. Intern J Clini Med 7: 399-418. 


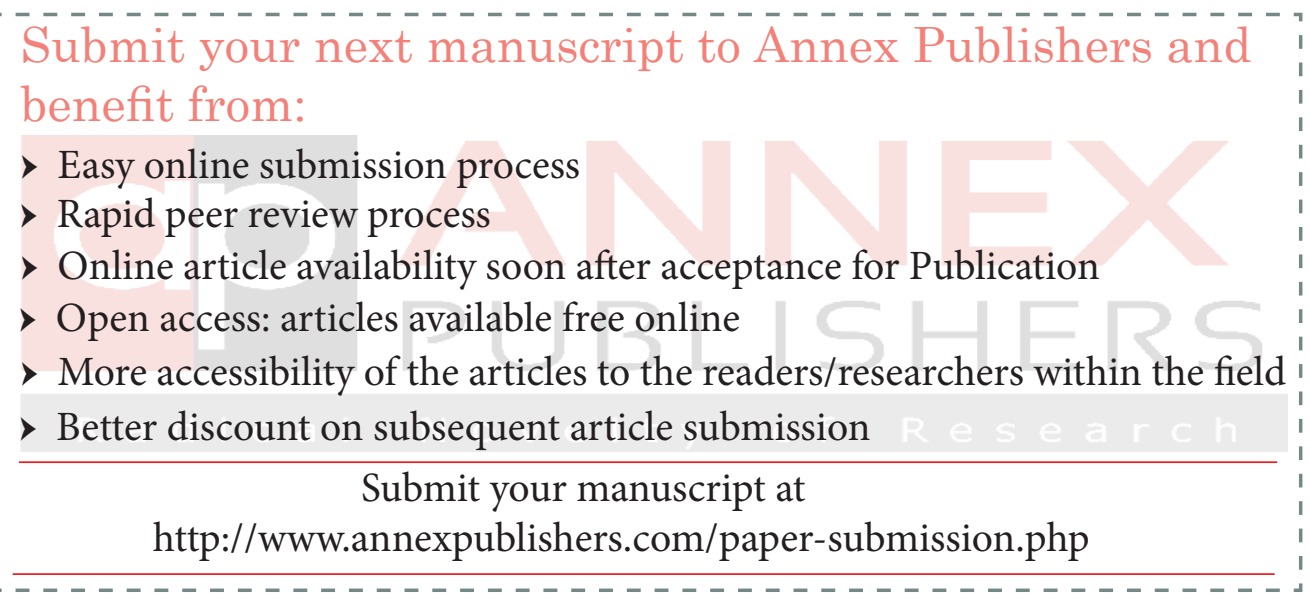

